\title{
EDITORIAL \\ Pediatric research: brief update on key objectives
}

Pediatric Research (2018) 84:2; https://doi.org/10.1038/s41390-0180087-8

Pediatric Research has three consistent key objectives. These objectives are: (i) to encourage young scientists to submit papers to Pediatric Research; (ii) to further broaden its scope and relevance, and (iii) to internationalize Pediatric Research. We have worked to further these goals and wish to report on our progress.

We are excited to report that our Early Career Investigator (ECI) series has been met with marked enthusiasm. We now have in place a process for selecting an $\mathrm{ECl}$ monthly, highlighting the chosen $\mathrm{ECl}$ in a bio-commentary, and, every other month, producing a pediapod of an interview with the chosen $\mathrm{ECl}$.

We are also excited to report that we have broadened the scope of the journal by creating several new sections: Quality Improvement, Environmental Health, and Behavior \& Development. Submissions to these sections are steadily increasing! And breaking news, we have added a section on Health Services Research! We and the editorial board have decided to broaden the scope of the journal even further by tearing down the silos of the sections. We will be listing all the topic areas that the editorial board deemed important for a research journal dedicated to Pediatrics. We will be ensuring that the editorial board has the expertise to provide rigorous review for all these topic areas. Look for the new masthead online shortly and in the first print issue of Volume 84 (July) of the journal!

To further broaden the scope, we have created an entirely new section entitled, Insights. Contributions to the Insights section include poems, in memoriams, retirement roastings, and historical/humanity pieces relevant to pediatric research. These contributions will use the commentary template. Another new addition to our commentaries are those solicited from parents/ advocacy groups when appropriate. Our inaugural Parent Commentary is currently in the works.

And finally, we report our progress on internationalizing the journal. We are seeking qualified individuals from low resource countries to join our editorial board. We are developing a system of published authors from low resource countries to serve as mentors/reviewers for international authors. The editorial team tracks the number of submissions from each world region, and the number of accepted articles from each world region. From 2015, submissions more than doubled from North America (203 to 440), Asia/Pacific Rim increased by 1.5 times (218 to 326), Europe increased by 1.7 times (197 to 332), Middle East/Africa almost tripled ( 22 to 65 ), and Mexico/Central/South America increased by 1.6 times ( 22 to 36 ). And, we are very pleased to announce that in this issue of Pediatric Research, we have an extraordinary diversity of countries of origin: 4 from USA, 3 from China, 2 from France, and 1 each from Australia, Austria, Egypt, Germany, Israel, Netherlands, Poland, Russia, Spain, Sweden, Tanzania, Uganda, and the United Kingdom!

For suggestions or comments, please contact us at the Editorial Office at Pediatric Research! We value your input in making Pediatric Research a benefit to all the societies' members.

Cynthia and Eleanor

Cynthia F. Bearer ${ }^{1}$ and Eleanor J. Molloy ${ }^{2}$

${ }^{1}$ Division of Neonatology, Department of Pediatrics, University of Maryland School of Medicine, Baltimore, MD, USA and ${ }^{2}$ Department of Paediatrics, Trinity College Dublin, Dublin, Ireland

Correspondence: Cynthia F. Bearer (cbearer@som.umaryland.edu) 